\title{
MODELING AND OPTIMIZATION OF THE ORANGE LEAVES OIL EXTRACTION PROCESS BY MICROWAVE-ASSISTED HYDRO-DISTILLATION: THE RESPONSE SURFACE METHOD BASED ON THE CENTRAL COMPOSITE APPROACH (RSM-CCD MODEL)
}

\section{Tan Phat Dao ${ }^{1,2}$, Duy Chinh Nguyen ${ }^{1}$, Thien Hien Tran', Phan Van Thinh ${ }^{3}$, Vu Quang Hieu ${ }^{1}$, Dai Viet Vo Nguyen ${ }^{4}$, Trinh Duy Nguyen ${ }^{1,5,6, *}$ and Long Giang Bach ${ }^{1,5,7, * *}$}

${ }^{1}$ NTT Hi-Tech Institute, Nguyen Tat Thanh University, Ho Chi Minh City, 70000, Vietnam

${ }^{2}$ Faculty of Chemical Engineering and Food Technology, Nguyen Tat Thanh University,

Ho Chi Minh City, 70000, Vietnam

${ }^{3}$ Dong Nai Technology University, Bien Hoa City, Dong Nai Province, Vietnam

${ }^{4}$ Faculty of Chemical and Natural Resources Engineering, Universiti Malaysia Pahang, Malaysia ${ }^{5}$ Graduate University of Science and Technology, Vietnam Academy of Science and Technology,

Ha Noi, Vietnam

${ }^{6}$ Department of Chemical Engineering, Pukyong National University, Busan, 608-739, Republic of Korea

${ }^{7}$ Department of Imaging System Engineering, Pukyong National University, Busan 608-737, Republic of Korea

*E-mail: ndtrinh@ntt.edu.vn, blgiang@ntt.edu.vn

\begin{abstract}
Although being a by-product after the harvest, orange leaves could be used to produce essential oil through extraction. Application of the essential oil extracted from orange leaves is diverse ranging from food flavoring to cosmetics. This study aimed to develop optimal conditions for microwave assisted hydro-distillation of essential oil from orange leaves. The selected optimization method is Response Surface Methodology in conjunction with the central composite experiment design. The factors that were varied for the production of the orange leaves oil extraction were material-to-water ratio, extraction time, and microwave power. Accordingly, a statistical model was established and Analysis of variance (ANOVA) was carried out to identify the set of factors that gives the highest essential oil yield. Optimization results revealed optimal conditions as follows, material and water ratio of 3.46:1 (mL/g), extraction time of $100.47 \mathrm{~min}$ and operating power of $471.58 \mathrm{~W}$. These conditions correspond to the essential oil yield of $0.43 \%$ with $92.1 \%$ reliability. In addition, we also analyze the produced essential oils by gas chromatography-mass spectrometry (GC-MS). The GC-MS results revealed that major components of essential oil were Sabinene (30.556 \%), Cis-Ocimene (10.139\%), and D-Limonene (9.682\%).

Keywords: Orange Leaves Oil, Microwave-assisted Hydro-distillation, Response Surface Methodology, GC-MS.
\end{abstract}

(C) RASĀYAN. All rights reserved

\section{INTRODUCTION}

Extraction technology plays a crucial role in the sustainability of the agro-food industry and the processing industry ${ }^{1-4}$. Nowadays, consumers tend to use products of natural origin which is health-beneficial and causes no side effects when taken accordingly.

Rasayan J. Chem., 12(2), 666-676(2019)

http://dx.doi.org/10.31788/RJC.2019.1225107

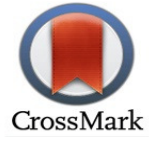


One of the components used in the production of such commodities is essential oils. Essential oils are valuable products composed of volatile substances. The oils are often isolated by various methods from plant organs or botanical species such as flowers, leaves, twigs, and seeds. Essential oils extracted from aromatic plants are often commercialized as export commodities and utilized in fragrance, cosmetics, pharmaceuticals and beverage industry. Popular products containing essential oils are air fresheners and deodorizers ${ }^{5-10}$. In medicine, almost all branches of medicine such as pharmacy, balneology, massage, and homeopathy recognized essential oils as important ingredients for drug production and popular components for various therapies and treatments.

Citrus fruits, similar to coffee and tea, are important goods for international trade and are widely cultivated globally. A significant proportion (60\%) of produced citrus are oranges. Orange has its origin in South-East Asia and it is the most widely used species of citrus fruits there. Orange constitutes a wide range of vitamins, especially vitamin $C$, and is a rich source of flavonoids, terpenes, potassium and calcium ${ }^{11-14}$. Among these constituents, flavonoids have been utilized to produce health supplements and recently, are found to exhibit hypolipidemic and inhibitory effects in cancer cells. In the cosmetics industry, the orange essential oil is used to aromatize products such as fragrance and creams. In the food industry, orange essential oil gained popularity due to its antimicrobial effect against bacteria and fungi. Other applications of the orange essential oil could include a solvent for extraction of fats and oils from an olive.

Recently, major technological and economic obstacles have hindered the development of extraction techniques ${ }^{15-18}$. Such bottlenecks could be more expensive energy, strict law on emission and/or requirement in safety control. Traditionally, oil extraction processes include pressing, solvent extraction, and different distillation techniques where heat is involved with temperature ranging from 130 to $150^{\circ} \mathrm{C}$. However, such techniques have various shortcomings including low oil yield, high toxicity stemming from hazardous solvents and extended extraction duration leading to increased costs ${ }^{19}$. To contribute to the environmental preservation and to enhance production efficiency, green techniques for extraction of oil from bio-products have been developed. Microwave-assisted extraction has been one of such technologies and is widely accepted in various industries due to its ability to reduce extraction time and to increase yield quantity and quality ${ }^{20-26}$. Due to electromagnetic waves with frequency ranging from $300 \mathrm{MHz}$ to $300 \mathrm{GHz}$, polar molecules in the biomaterial are rapidly rotated, in turn generating heat in the interior of the material. The main advantage of microwave extraction is that it is capable of breaking cell walls and oil sacs, quickly freeing oil and constituents inside to the outside solvent medium. Therefore, the extraction efficiency could be improved.

Operating conditions in the extraction process have been investigated individually with respect to the production of essential oils. However, this approach is inefficient in terms of time and costs since the interaction between conditions is not taken into account and numerous experimental attempts are required. RSM is an optimization technique devised to overcome these disadvantages ${ }^{27,28}$. The method aims to describe a desired response or an outcome of interest with respect to a set of process variables through the use of statistical techniques. Benefits of RSM are numerous. In addition to readily available, efficient and simple experimental designs for the method ${ }^{29-44}$. RSM could also reduce the number of experiment trials and solve issues related to linear and non-linear multivariate regression.

The objective of the current study is to maximize the amount of extracted essential oil orange leaves. The method of extraction is microwave-assisted hydro-distillation method and the process is optimized by RSM. We considered variables that are relevant and useful to the possible up-scale process including material and water ratio, extraction time, microwave power and efficiency. The responses were the measured yield of essential oil. A statistical model was established to model extraction conditions and levels of experimental conditions were determined by central composite design (CCD). ANOVA analysis was adopted to assess the effect of the process variables on both of the responses. Optimal yields of essential oil were then predicted and experimentally verified.

\section{Materials and Chemicals}

\section{EXPERIMENTAL}

Orange leaves were taken from local markets in Vietnam. The material was washed several times with water to remove impurities and allowed to dry naturally. Then a grinder (Sunhouse, about 2-3mm) was used 
to grind the material. Finally, the material was placed in a Clevenger type apparatus, connected to a domestic microwave oven (SAMSUNG MW71E) for microwave assisted hydro-distillation (MAHD) operation for extraction of essential oil as described in Fig.-1 and Fig.-2.

Anhydrous sodium sulfate (Na2SO4) was purchased from Sigma Aldrich (US). Deionized water produced by Milli-Q purification system (Millipore, USA) was used as a solvent to extract orange leaves oil.

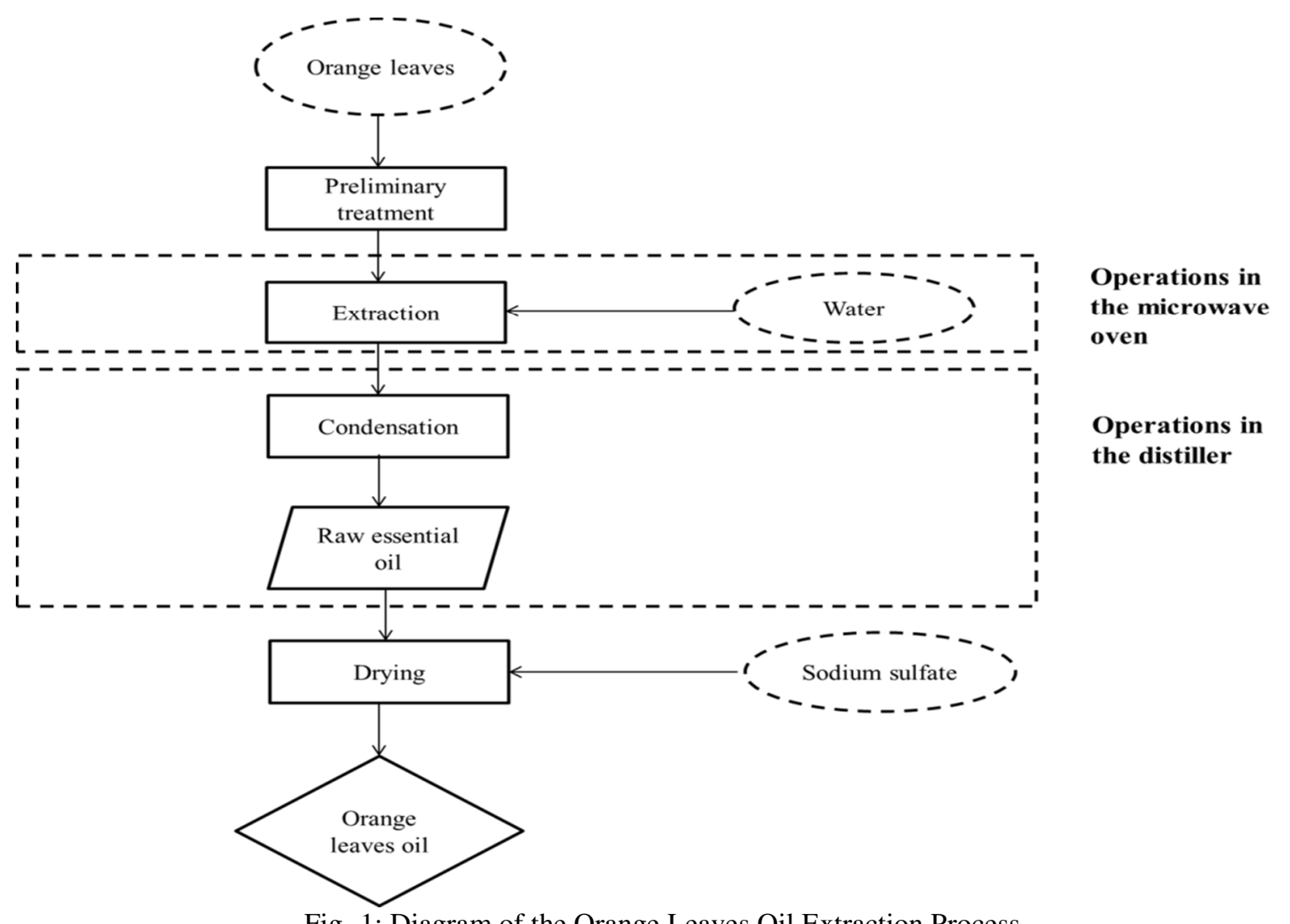

Fig.-1: Diagram of the Orange Leaves Oil Extraction Process

\section{Experimental Design with RSM}

To optimize factors influencing the hydro-distillation process, the response surface methodology was adopted to maximize essential oil yield. Considered factors include water and material ratio (A), extraction time (B), and microwave power (C). MAHD optimal code was determined following the central composite design, where the response variable and the experiment matrix designs were shown in Table-1. Design Expert software version 11 was employed to carry out ANOVA, regression, statistical tests and plotting. In order to verify the adequacy of the developed model, optimal conditions were verified by an actual experimental attempt.

Table-1: Independent Variables Matrix and their Encoded Levels for RSM Model.

\begin{tabular}{c|c|c|c|c|c|c|c}
\hline \multirow{2}{*}{ Code } & Name & \multirow{2}{*}{ Units } & \multicolumn{5}{|c}{ Levels } \\
\cline { 4 - 8 } & & & $-\alpha$ & -1 & 0 & +1 & $+\alpha$ \\
\hline $\mathrm{A}$ & Material and water ratio & $\mathrm{mL} / \mathrm{g}$ & 1.3 & 2 & 3 & 4 & 4.7 \\
\hline $\mathrm{B}$ & Extraction time & $\mathrm{Min}$ & 40 & 60 & 90 & 120 & 140 \\
\hline $\mathrm{C}$ & Microwave power & $\mathrm{W}$ & 198 & 300 & 450 & 600 & 702 \\
\hline
\end{tabular}

The yield of orange leaves oil extracted (Y) was calculated as follows to evaluate the performance of MAHD:

$$
Y(\%)=\frac{\text { Volume of essential oil }(\mathrm{ml})}{\text { Amount of raw materials }(\mathrm{g})} 100 \%
$$




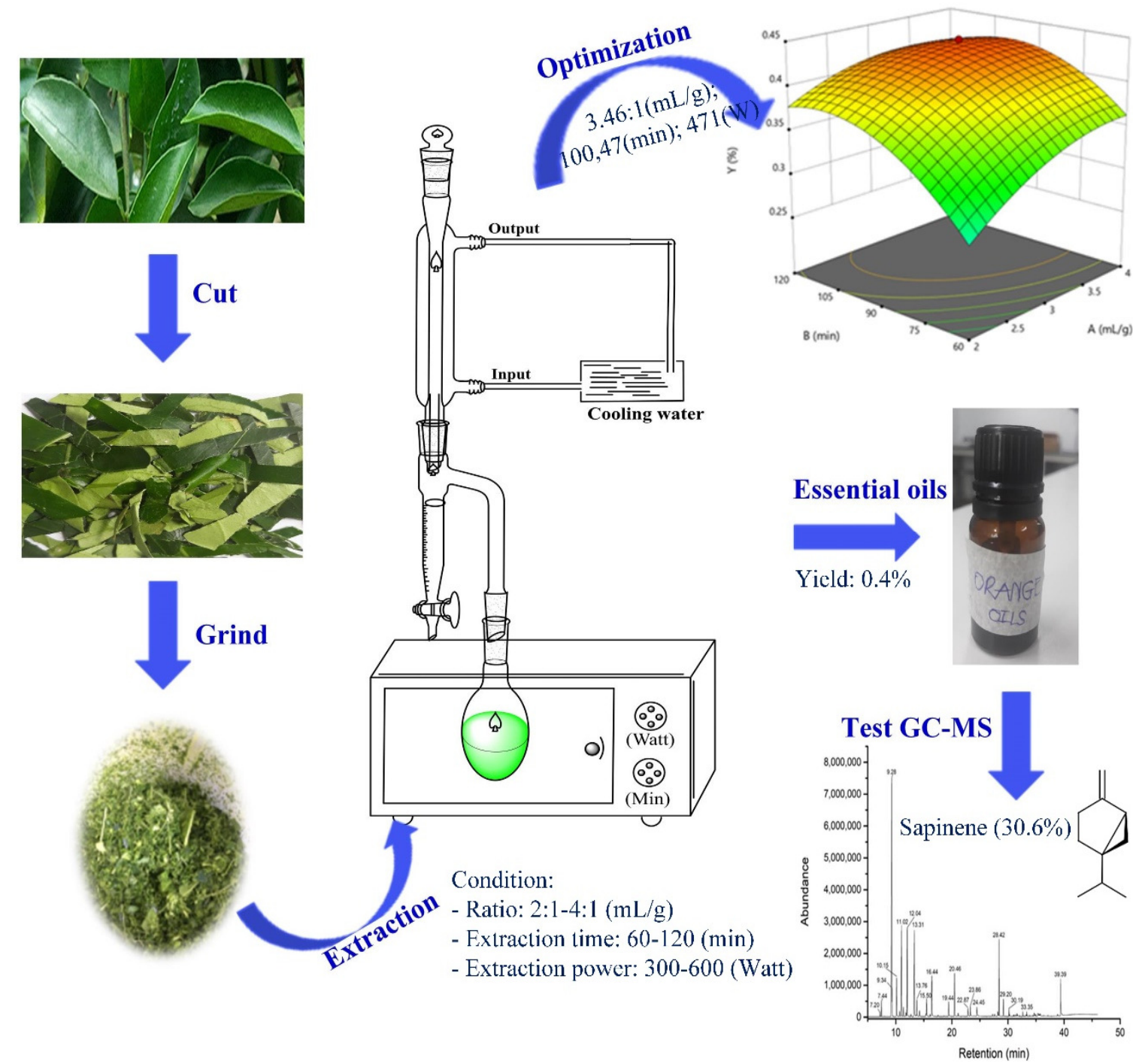

Fig.-2: The experimental process including preparation of orange leaves, microwave-assisted hydro-distillation unit and analysis of the obtained oil samples.

\section{Analysis of Sample}

Gas Chromatography-Mass Spectrometry (GC-MS) was used to analyze the composition of the essential oils of all extraction methods. $25 \mu \mathrm{L}$ sample of essential oil in $1.0 \mathrm{~mL}$-hexane. Name of the equipment: GC Agilent 6890N, MS 5973 inert with HP5-MS column, head column pressure 9.3psi. GC-MS system operated at the following conditions: carrier gas $\mathrm{He}$; flow rate $1.0 \mathrm{~mL} / \mathrm{min}$; split 1:100; injection volume 1.0 $\mu \mathrm{L}$; injection temperature $250^{\circ} \mathrm{C}$. Oven temperature progressed from an initial hold at $50^{\circ} \mathrm{C}$ for 2 min and a rise to $80^{\circ} \mathrm{C}$ at $2^{\circ} \mathrm{C} / \mathrm{min}$, and then to $150^{\circ} \mathrm{C}$ at $50 \mathrm{C} / \mathrm{min}$, continue rising to $200^{\circ} \mathrm{C}$ at $10^{\circ} \mathrm{C} / \mathrm{min}$ and rise to $300^{\circ} \mathrm{C}$ at $20^{\circ} \mathrm{C} / \mathrm{min}$ for $5 \mathrm{~min}$.

\section{Building Response Surface Model}

\section{RESULTS AND DISCUSSION}

Experimental results (20 experiments), produced by the design method of complex CCD center, and predictions by Design-Expert 11 are shown in Table-2. To be specific, 20 experiments including six axial points, six center points, and eight factorials, were devised and attempted to derive the input data for the approximation of response function. The experimental and predicted result of Table-2 suggested the impact of the three process factors on the yield. The estimated quadratic model is described as follows (2): $\mathrm{Y}=0.4162+0.0270 \mathrm{~A}+0.0343 \mathrm{~B}+0.0270 \mathrm{C}-0.0125 \mathrm{AB}-0.025 \mathrm{AC}-0.0125 \mathrm{BC}-0.0205 \mathrm{~A}^{2}-0.0382 \mathrm{~B}^{2}-$ $0.0382 C^{2}(2)$. 
The ANOVA results for the quadratic model of essential oil yield were summarized in Table-3. The main terms in the ANOVA table included: water and material ratio (A), microwave power level (B), extraction time $(C)$, interaction terms $(\mathrm{AB}, \mathrm{BC}, \mathrm{AC})$ and second-order effects $\left(\mathrm{A}^{2}, \mathrm{~B}^{2}\right.$, and $\left.\mathrm{C}^{2}\right)$. Based on the F-value, it is suggested that the model was significant and the odds of noise that could cause such F-value is minimal, approximately $0.01 \%$. The LOF F-value of 0.6782 is also desirable, implying that the LOF was not significant relative to the pure error and this experimental design model is suitable. In addition, the predicted $\mathrm{R}^{2}$ of 0.7344 concurred with the adjusted $\mathrm{R}^{2}$ of 0.9918 . AP ratio was also greater than 4 , which indicates signal adequacy. Therefore, this model could be used to navigate the design space.

Table-2: Box-Behnken Design and Observed Responses

\begin{tabular}{|c|c|c|c|c|c|c|}
\hline \multirow{2}{*}{$\begin{array}{l}\text { S. } \\
\text { No. }\end{array}$} & \multicolumn{3}{|c|}{ Experimental Parameters } & \multicolumn{2}{|c|}{$\mathrm{Y}(\%)$} & \multirow[b]{2}{*}{ Residual } \\
\hline & $\begin{array}{c}\text { A (Material and } \\
\text { Water Ratio, } \mathrm{mL} / \mathrm{g} \text { ) }\end{array}$ & $\begin{array}{l}\text { B (Extraction } \\
\text { Time, Min) }\end{array}$ & $\begin{array}{c}\text { C (Microwave } \\
\text { Power, W) }\end{array}$ & Actual & Predicted & \\
\hline 1 & 2.0 & 60 & 300 & 0.20 & 0.1811 & 0.0189 \\
\hline 2 & 4.0 & 60 & 300 & 0.30 & 0.3100 & -0.0100 \\
\hline 3 & 2.0 & 120 & 300 & 0.30 & 0.2996 & 0.0004 \\
\hline 4 & 4.0 & 120 & 300 & 0.40 & 0.3785 & 0.0215 \\
\hline 5 & 2.0 & 60 & 600 & 0.30 & 0.3100 & -0.0100 \\
\hline 6 & 4.0 & 60 & 600 & 0.35 & 0.3389 & 0.0111 \\
\hline 7 & 2.0 & 120 & 600 & 0.40 & 0.3785 & 0.0215 \\
\hline 8 & 4.0 & 120 & 600 & 0.35 & 0.3575 & -0.0075 \\
\hline 9 & 1.3 & 90 & 450 & 0.30 & 0.3128 & -0.0128 \\
\hline 10 & 4.7 & 90 & 450 & 0.40 & 0.4035 & -0.0035 \\
\hline 11 & 3.0 & 40 & 450 & 0.25 & 0.2505 & -0.0005 \\
\hline 12 & 3.0 & 140 & 450 & 0.35 & 0.3658 & -0.0158 \\
\hline 13 & 3.0 & 90 & 198 & 0.25 & 0.2628 & -0.0128 \\
\hline 14 & 3.0 & 90 & 702 & 0.35 & 0.3535 & -0.0035 \\
\hline 15 & 3.0 & 90 & 450 & 0.40 & 0.4162 & -0.0162 \\
\hline 16 & 3.0 & 90 & 450 & 0.40 & 0.4162 & -0.0162 \\
\hline 17 & 3.0 & 90 & 450 & 0.40 & 0.4162 & -0.0162 \\
\hline 18 & 3.0 & 90 & 450 & 0.40 & 0.4162 & -0.0162 \\
\hline 19 & 3.0 & 90 & 450 & 0.45 & 0.4162 & -0.0162 \\
\hline 20 & 3.0 & 90 & 450 & 0.45 & 0.4162 & -0.0162 \\
\hline
\end{tabular}

The yield of essential oil could be predicted using the above model. To validate the model, residuals of 20 runs and yields of oil were plotted in Fig.-3. Figure-3A plotted actual experiment yield values against predicted values. Visually, the distribution of data points follows the 45-degree line, indicating the consistency between the predicted value and the actual experimental value. Figure-3B indicated that the residuals of experimental yields clearly follow a random pattern. Figure-3A, which plotted predicted versus against actual values, also indicated close proximity of scattered data points to the 45-degree line, suggesting the reasonable predictive accuracy of the model and no violation of assumptions regarding the independence of variables and constant variance. Figure 3C depicted studentized residuals against corresponding probabilities. It is revealed that data points were almost on a straight line, suggesting no serious deviation and reasonable fit of the model. 
RASĀYAN J. Chem.

Vol. 12 | No. 2 |666 - 676| April - June | 2019

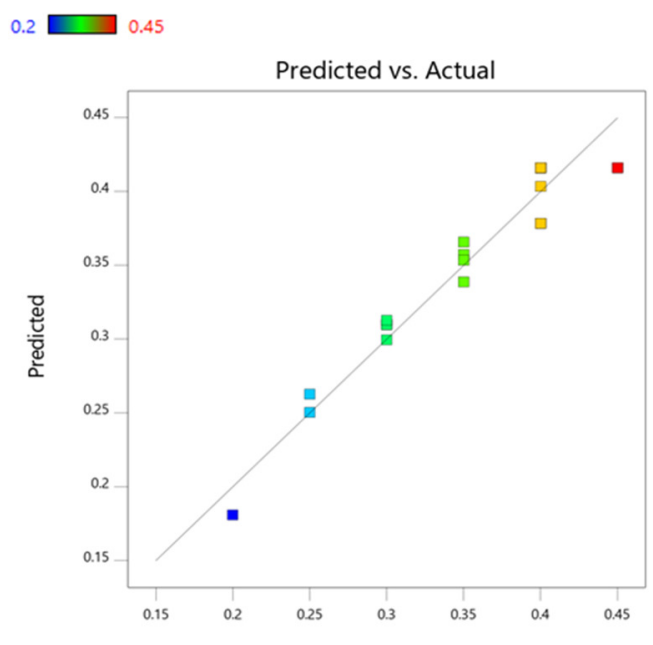

Actual

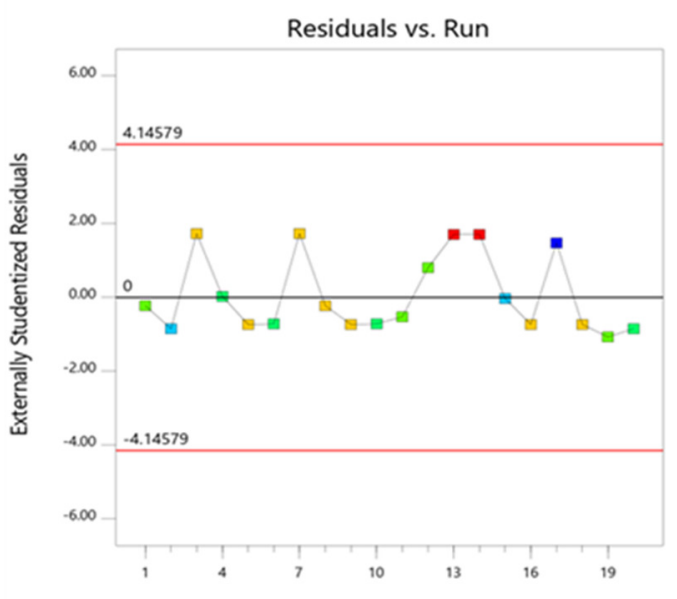

Run Number

(B)

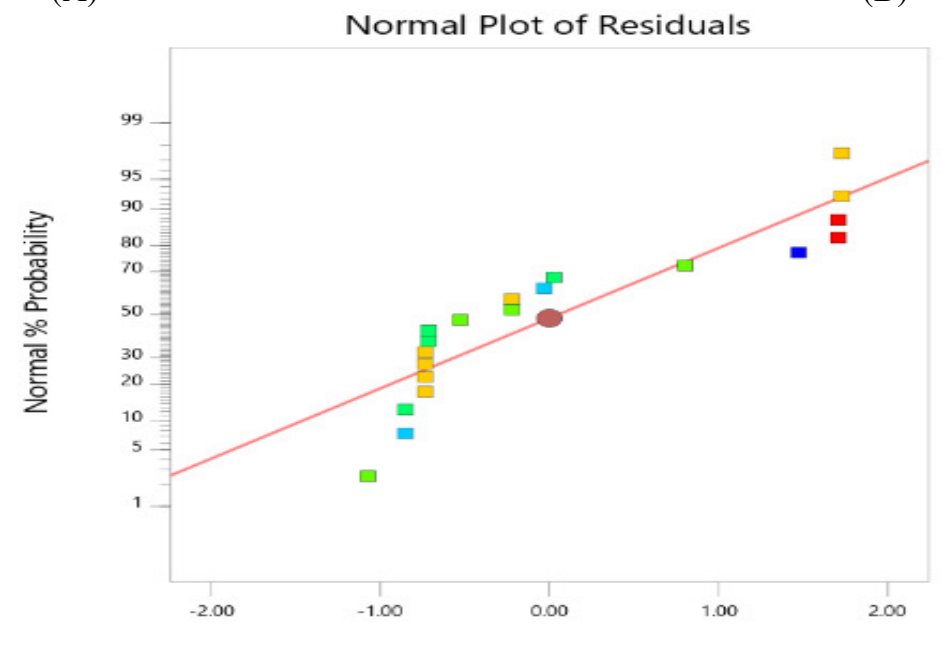

Externally Studentized Residuals

(C)

Fig.-3: Estimation of Model Precision (A) Comparison between Actual Values and Predicted Values and (B) Plot of Internally Studentized Residuals versus the Actual Run, and (C) The Normal \% Probability Plot.

Table-3: ANOVA Results of the Response Function

\begin{tabular}{c|c|c|c|c|c|c|c}
\hline Source & $\begin{array}{c}\text { Sum of } \\
\text { Squares }\end{array}$ & $\mathrm{dF}$ & $\begin{array}{c}\text { Mean } \\
\text { Square }\end{array}$ & F-Value & $\mathrm{p}$-Value & \multicolumn{2}{|c}{ Comment } \\
\hline Model & 0.0844 & 9 & 0.0094 & 16.77 & $<0.0001$ & Significant & $\mathrm{SD}=0.0237$ \\
\hline $\mathrm{A}$ & 0.0099 & 1 & 0.0099 & 17.74 & 0.0018 & Significant & Mean $=0.3500$ \\
\hline $\mathrm{B}$ & 0.0160 & 1 & 0.0160 & 28.69 & 0.0003 & Significant & $\mathrm{CV}(\%)=6.76$ \\
\hline $\mathrm{C}$ & 0.0099 & 1 & 0.0099 & 17.74 & 0.0018 & Significant & $\mathrm{R}^{2}=0.9378$ \\
\hline $\mathrm{AB}$ & 0.0013 & 1 & 0.0013 & 2.23 & 0.1658 & & $\mathrm{AP}=14.0606$ \\
\hline $\mathrm{AC}$ & 0.0050 & 1 & 0.0050 & 8.94 & 0.0136 & Significant & $\mathrm{Adj} \mathrm{R}^{2}=0.8819$ \\
\hline $\mathrm{BC}$ & 0.0013 & 1 & 0.0013 & 2.23 & 0.1658 & & Pred $^{2}=0.7344$ \\
\hline $\mathrm{A}^{2}$ & 0.0061 & 1 & 0.0061 & 10.86 & 0.0081 & Significant & \\
\hline
\end{tabular}


RASĀYAN J. Chem.

Vol. 12 | No. 2 |666 - 676| April - June | 2019

\begin{tabular}{c|c|c|c|c|c|c|c}
\hline $\mathrm{B}^{2}$ & 0.0210 & 1 & 0.0210 & 37.61 & 0.0001 & Significant & \\
\hline $\mathrm{C}^{2}$ & 0.0210 & 1 & 0.0210 & 37.61 & 0.0001 & Significant & \\
\hline Residual & 0.0056 & 10 & 0.0006 & & & & \\
\hline Lack of Fit & 0.0023 & 5 & 0.0005 & 0.6782 & 0.6598 & Not Significant & \\
\hline Pure Error & 0.0033 & 5 & 0.0007 & & & & \\
Cor Total & 0.0900 & 19 & & & & & \\
\hline
\end{tabular}

\section{Optimization of Experimental Procedures}

The interaction effects of parameters on the response were demonstrated by three-axis response surfaces and two-axis plots. From Fig.-4, it is revealed that all three experimental parameters exerted significant influence on the yield of the Orange leaves oil extraction. In addition, the interactions between different functions (ratio water and raw materials and extraction time, ratio water and raw materials and microwave power, microwave power and extraction time) also exhibited very significant influence on the extraction yield. From Fig.-4, it could be observed that general trends of the three factors are similar. To be specific, an increase in any of the three factors induces oil yield to rise until oil yield reaches a certain point, where yield stops rising, and eventually, starts diminishing. Optimization results were calculated as: $\mathrm{A}=3.46(\mathrm{~mL} / \mathrm{g})$, $\mathrm{B}=100.47(\mathrm{~min})$, and $\mathrm{C}=471.58(\mathrm{~W})$ with desirability of $92.1 \%$. These correspond with the orange leaves oil yield of $0.43 \%$.

\section{Validation of the Predictive Model}

The data from Table-4 display the optimum conditions resulted from optimization. Accordingly, material and water ratio of $3.46: 1(\mathrm{~mL} / \mathrm{g})$, the time of 100.47 minutes and $471.58 \mathrm{~W}$ operating power yielded the highest efficiency of $0.43 \%$. This number approximates to the actual yield, conducted with almost identical conditions, of $0.4 \%$. This result reaffirmed the validity of the model, suggesting that the model accurately predicted yield values. These results are in line with previous research results in which the yield of essential oils extracted from orange leaves ranged from $0.19-0.28 \%$ using steam distillation for $2 \mathrm{~h}^{45-46}$, and reached $0.23 \%$ for steam distillation for $5 \mathrm{~h}{ }^{47}$. Obviously, MAHD showed higher efficiency and shorter extraction time. More specific, the yield of orange leaves oil (0.43\%) using MAHD was also higher than that of steam distillation (0.19-0.28\%) with an extraction time of $100 \mathrm{~min}$. These results confirmed the suitability MAHD when it comes to essential oil extraction from orange leaves.

Table-4: The Experimental Results using Optimum Condition Comparison with Predicted Results

\begin{tabular}{c|c|c|c|c}
\hline & $\begin{array}{c}\text { Material and Water Ratios } \\
(\mathrm{g} / \mathrm{mL})\end{array}$ & $\begin{array}{c}\text { Extraction Time } \\
(\mathrm{min})\end{array}$ & $\begin{array}{c}\text { Microwave } \\
\text { Power }(\mathrm{W})\end{array}$ & $\begin{array}{c}\text { The Yield of } \\
\text { Essential Oil }(\%)\end{array}$ \\
\hline Predicted & 3.46 & 100.47 & 471.58 & 0.43 \\
\hline Actual & 3.46 & 100 & 471 & 0.4 \\
\hline
\end{tabular}

\section{GC-MS Analysis Results}

The chemical composition of orange leaves oil was presented together with the retention indices in Table-5 and Fig.-5. The GC-MS analysis identified 28 components in total. The major chemical compounds were Sabinene (30.556\%) followed by Cis-Ocimene (10.139\%), D-Limonene (9.682\%), 3-Carene (9.102\%), $\beta$-Elemenne (6.060\%), Linalool (5.240\%).

In a previous study ${ }^{1}$, the aforementioned components were also found in the orange leaves oil, although in varying amounts. To be specific, previously recognized components were Sabinene (16.03\%), 3-Carene (7.53\%), and limonene (3.71\%). It also showed that the number of components found in this study is higher than that in previous research. It is worth nothing that chemical composition of the essential oil could vary depending on geographical location and season of harvest, plant age and method extraction ${ }^{48}$. 
RASĀYAN J. Chem.

Vol. 12 | No. 2 |666 - 676| April - June | 2019

(A)

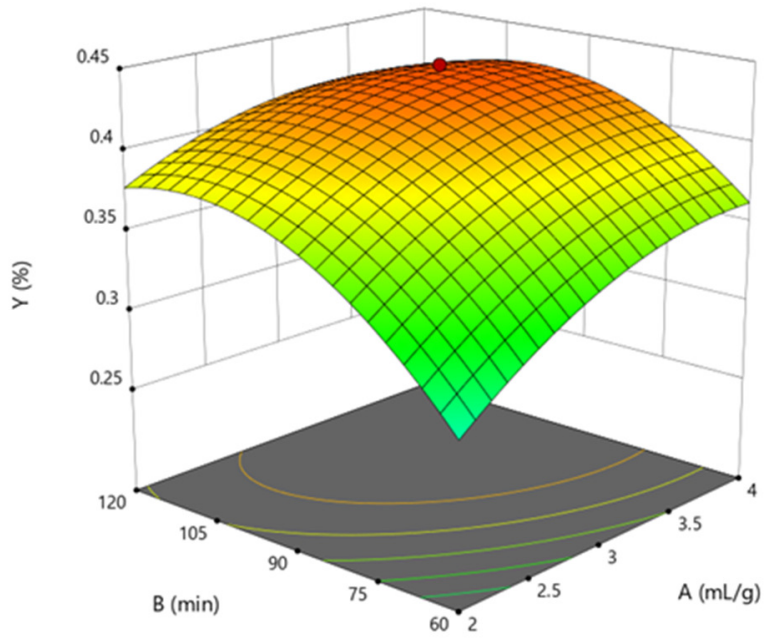

(B)

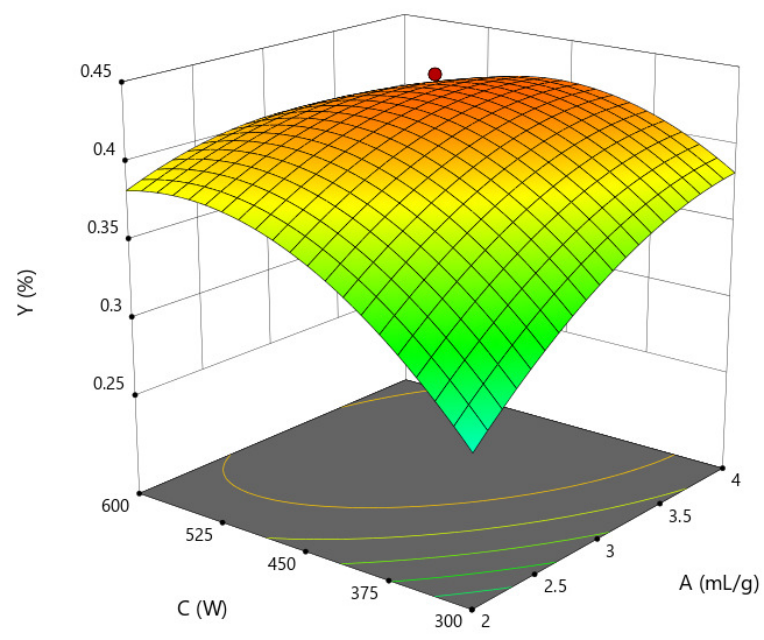

(C)

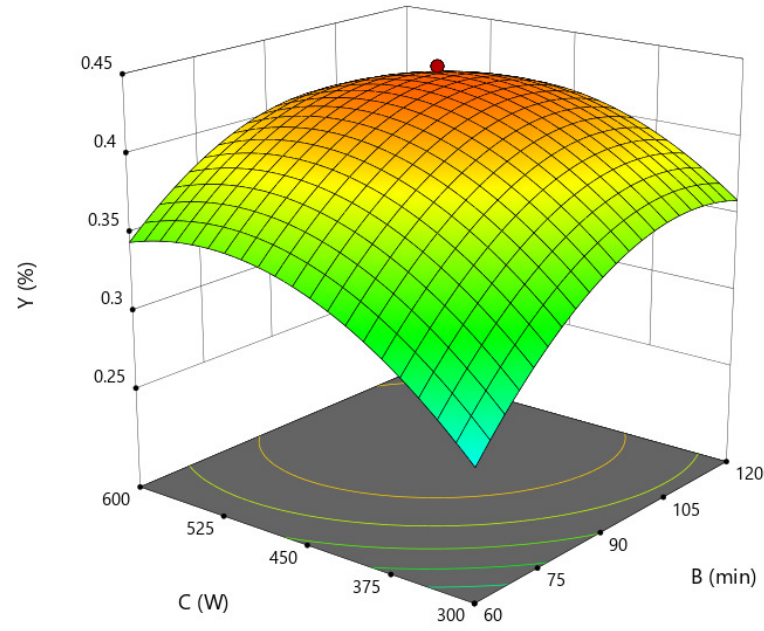

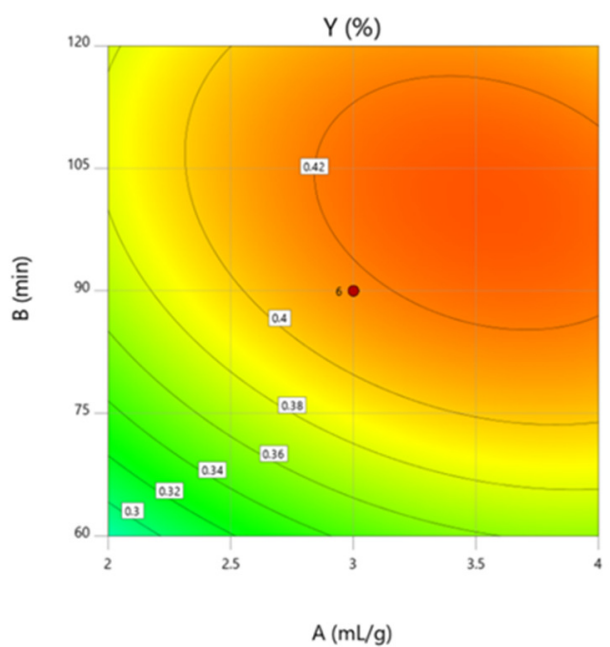
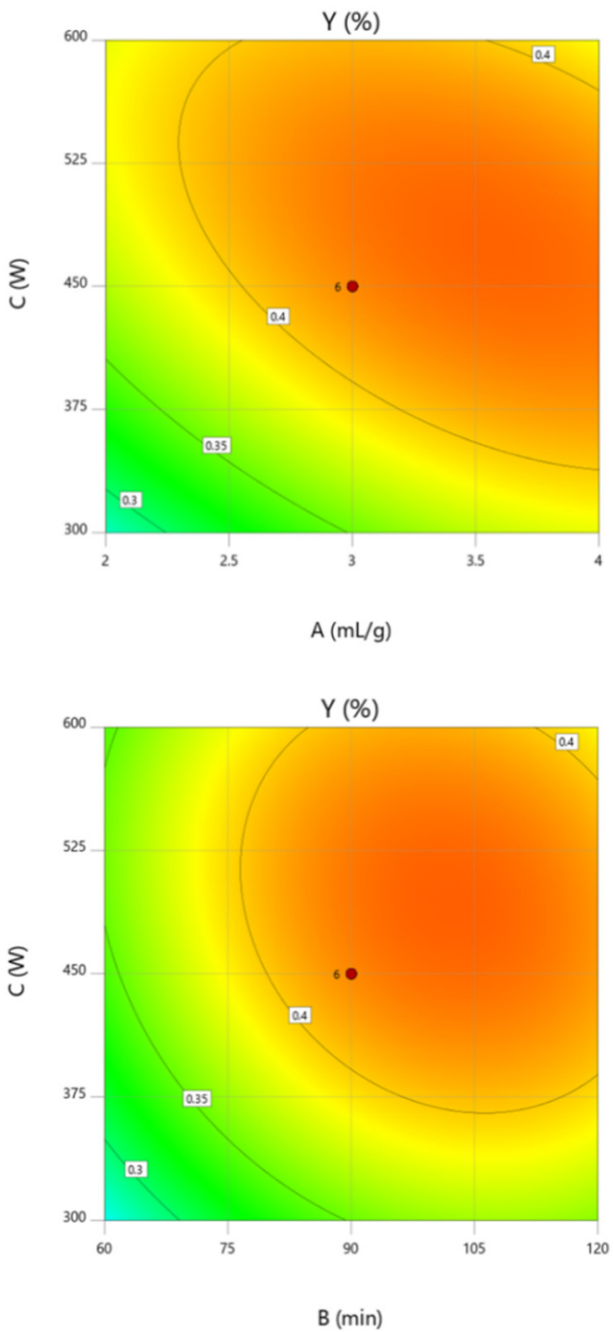

Fig.-4: 3D Response Surface Plots of the Interaction of Y with (A) Ratio Water and Raw Materials and Extraction Time, (B) Ratio Water and Raw Materials and Microwave Power, (C) Microwave Power and Extraction Time 


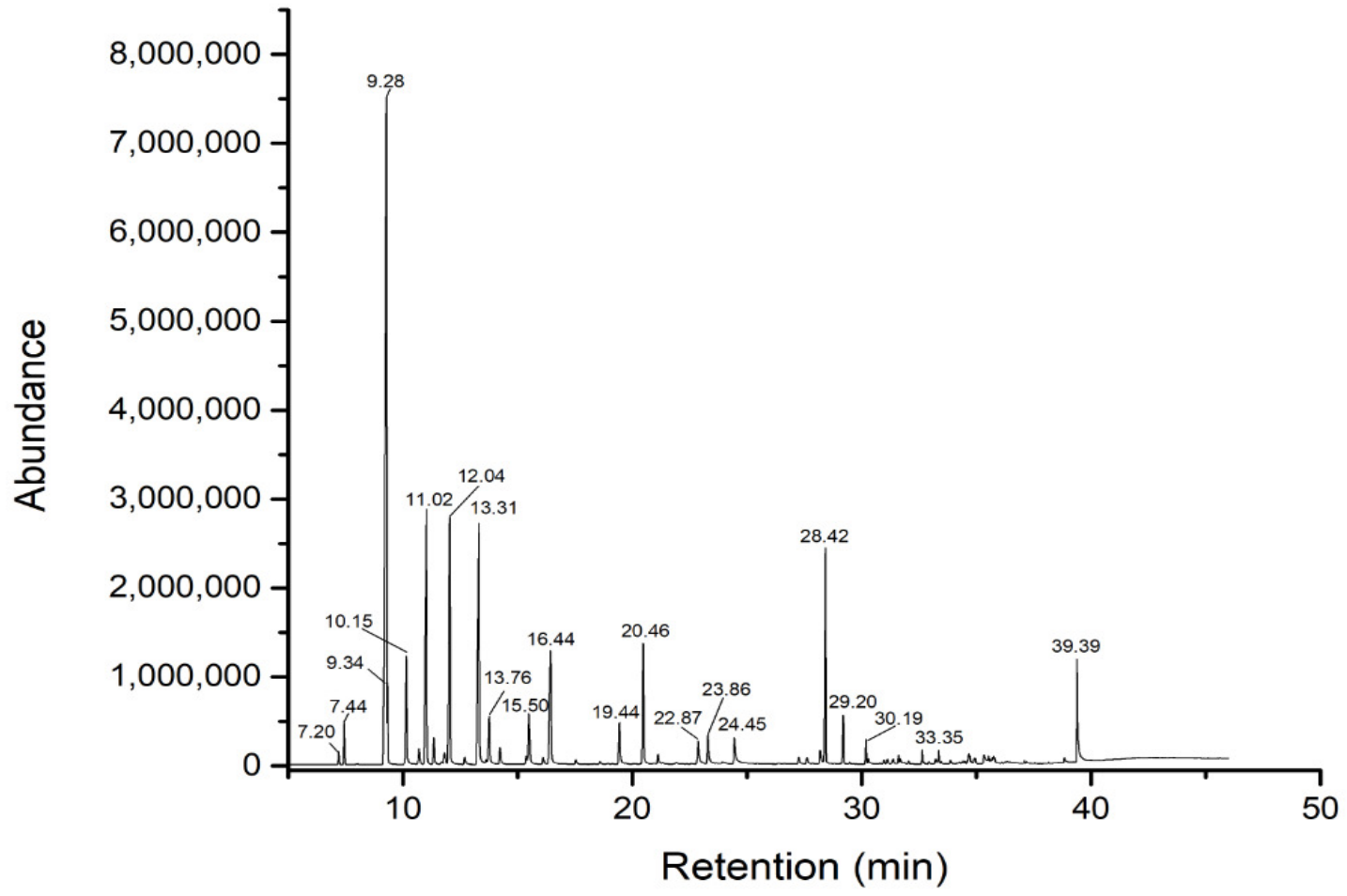

Fig.-5: GC-MS Results of Orange Leaves Oil Extraction by MAHD Method Table-5: Chemical Composition of Orange Leaves Oil

\begin{tabular}{c|c|c|c|c|c}
\hline No. & Component & MAHD $(\%)$ & No. & Component & MAHD(\%) \\
\hline 1 & $2,4(10)$-Thujadiene & 0.339 & 15 & Linalool & 5.240 \\
\hline 2 & 1 R- $\alpha$-Pinene & 1.090 & 16 & $\beta$-Citronellal & 1.552 \\
\hline 3 & Sabinene & 30.556 & 17 & L-4-terpineneol & 4.391 \\
\hline 4 & $\beta$-Pinene & 1.618 & 18 & $\alpha$-Terpineol & 0.318 \\
\hline 5 & $\beta$-Mycene & 3.654 & 19 & $\beta$-Cotronellol & 1.059 \\
\hline 6 & $\alpha$-Phellandrene & 0.588 & 20 & $\beta$-Citral & 1.123 \\
\hline 7 & 3 -Carene & 9.102 & 21 & $\alpha$-Citral & 1.258 \\
\hline 8 & $\alpha$-Terpinen & 0.939 & 22 & $\beta$-Elemen & 0.609 \\
\hline 9 & o-Cymol & 0.542 & 23 & $\beta$-Elemenne & 6.060 \\
\hline 10 & D-Limonene & 9.682 & 24 & Caryophyllene & 1.325 \\
\hline 11 & Cis-Ocimene & 10.139 & 25 & $\alpha$-Caryophyllene & 0.617 \\
\hline 12 & $\gamma$-Terpinene & 1.911 & 26 & Elemol & 0.277 \\
\hline 13 & Terpineol & 0.658 & 27 & Caryophyllene oxide & 0.353 \\
\hline
\end{tabular}

CONCLUSION

The present study explore microwave-assisted hydro-distillation of essential oil from orange leaves using response surface methodology (RSM). A total of 20 experimental runs following the Box-Behnken design was generated and attempted to generate the data for RSM procedure. The condition obtained an optimum yield of $0.43 \%$ with the material and water ratio of 3.46:1 (mL/g), the extraction time of $100.47 \mathrm{~min}$, and $471.58 \mathrm{~W}$ operating power. The validity of the constructed model was verified by the determination 
coefficients $\left(R^{2}=0.9378\right.$, Adj. $\left.R^{2}=0.8819\right)$ and the significance of the lack of fit $(p>0.05)$. This study serves as the precursor for the production of industrial scale by discovering optimal conditions of orange leaf oil extraction. In addition, not only did the MAHD method give very high oil yield, but the results of GC-MS also showed that the beneficial components existed in very high content in the essential oil.

\section{REFERENCES}

1. K. Wu, T. Ju, Y. Deng and J. Xi, Trends in Food Science \& Technology, 66, 166(2017), DOI:10.1016/j.tifs.2017.06.011

2. B. K. Tiwari, TrAC Trends in Analytical Chemistry, 71, 100(2015), DOI: 10.1016/j.trac.2015.04.013

3. H. W. Huang, C. P. Hsu, B. B. Yang and C. Y. Wang, Trends in Food Science \& Technology, 33(1), 54(2013), DOI:10.1016/j.tifs.2013.07.001

4. Z. Zhu and C. Y. Cheng, Hydrometallurgy, 107(1-2), 1(2011), DOI:10.1016/j.hydromet.2010.12.015

5. V. Radenkovs, J. Kviesis, K. Juhnevica-Radenkova, A. Valdovska, T. Püssa, M. Klavins and I. Drudze, Plants, 7, 90(2018), DOI:10.3390/plants7040090

6. M. D. Ibáñez and M. A. Blázquez, Plants, 7, 7(2018), DOI:10.3390/plants7040079

7. B. Salehi, Z. Stojanović-Radić, J. Matejić, F. Sharopov, H. Antolak, D. Kręgiel, S. Sen, M. Sharifi-Rad, K. Acharya, R. Sharifi-Rad, M. Martorell, A. Sureda, N. Martins and J. Sharifi-Rad, Plants, 7, 70(2018), DOI:10.3390/plants7030070,

8. L. Bendifallah, R. Belguendouz, L. Hamoudi and K. Arab, Plants, 7, 44(2018), DOI: 10.3390/plants7020044

9. $\quad$ N. S. Dosoky and W. N. Setzer, Plants, 7, 19(2018), DOI:10.3390/plants7010019

10. T. H. Tran, H. H. H. Nguyen, D. C. Nguyen, T. Q. Nguyen, H. Tan, L. T. H. Nhan, D. H. Nguyen, L. D. Tran, S. T. Do and T. D. Nguyen, Processes, 6, 206(2018), DOI:10.3390/pr6110206

11. A. C. Matheyambath, P. Padmanabhan and G. Paliyath, Encyclopedia of Food and Health, 136(2016)

12. A. Mditshwa, L. S. Magwaza, S. Z. Tesfay and U. L. Opara, Scientia Horticulturae, 218, 95(2017), DOI:10.1016/j.scienta.2017.02.024

13. S. Cirmi, M. Navarra, J. V. Woodside and M. M. Cantwell, Pharmacological Research, 133, 187(2018), DOI:10.1016/j.phrs.2018.05.008

14. Y. Jo, H. A. Nam, S. R. Ramakrishnan, M. E. Baek, S. B. Lim, J. H. Kwon, Scientia Horticulturae, 236, 265(2018), DOI:10.1016/j.scienta.2017.12.029

15. C. M. G. C. Renard, LWT, 93, 390(2018), DOI:10.1016/j.lwt.2018.03.063

16. S. S. Nadar, P. Rao, V. K. Rathod, Food Research International, 108, 309(2018), DOI:10.1016/j.foodres.2018.03.006

17. A. Etxabide, T. Garrido, J. Uranga and P. Guerrero, International Journal of Biological Macromolecules, 120B, 2094(2018), DOI:10.1016/j.ijbiomac.2018.09.030

18. R. K. Saini and Y. S. Keum, Food Chemistry, 240, 90(2018), DOI:10.1016/j.foodchem.2017.07.099

19. M. Mahfud, D. K. Y. Putri, I. E. P. Dewi and H. S. Kusuma, Rayasan Journal of Chemistry, 10(1), 86(2017), DOI:10.7324/RJC.2017.1011562

20. F. G. C. Ekezie, D.W. Sun and J. H. Cheng, Trends in Food Science \& Technology, 67, 160(2017), DOI:10.1016/j.tifs.2017.06.006

21. M. Vinatoru, T. J. Mason and I. Calinescu, TrAC Trends in Analytical Chemistry, 97, 159(2017), DOI:10.1016/j.trac.2017.09.002

22. A. Martín and A. Navarrete, Current Opinion in Green and Sustainable Chemistry, 11, 70(2018), DOI: $10.1016 / j . \operatorname{cogsc} .2018 .04 .019$

23. N. A. Yahya, N. Attan and R. A. Wahab, Food and Bioproducts Processing, 112, 69(2018), DOI:10.1016/j.fbp.2018.09.002

24. T. V. Pham, T. T. Nguyen, D. T. Nguyen, T. V. Thuan, P. Q. T. Bui, V. N. D. Viet and L. G. Bach, Journal of Nanoscience and Nanotechnology, 19(2), 1122(2019), DOI:10.1166/jnn.2019.15926

25. T. V. Pham, D. T. Nguyen, T. T. Nguyen, V. T. T. Ho, P. Q. T. Bui and L. G. Bach, Solid State Phenomena, 279, 230(2018), DOI:10.4028/www.scientific.net/SSP.279.230 
RASĀYAN J. Chem.

Vol. 12 | No. 2 |666 - 676| April - June | 2019

26. H. Q. Pham, T. T. Huynh, A. V. Nguyen, A. T. N. Mai, V. T. T. Phan, L. G. Bach, D. T. Nguyen and V. T. T. Ho, Solid State Phenomena, 279, 181(2018), DOI:10.4028/www.scientific.net/SSP.279.181

27. H. S. Kusuma and M. Mahfud, Rasayan Journal of Chemistry, 10(3), 861(2017), DOI:10.7324/RJC.2017.1031763

28. L. Qadariyah, S. N. Syahir, A. Fyadlon, D.S. Bhuana and M. Mahfud, Rasayan Journal of Chemistry, 10(3), 952(2017). DOI:10.7324/RJC.2017.1031803

29. M. A. Bezerra, R. E. Santelli, E. P. Oliveira, L. S. Villar and L. A. Escaleira, Talanta, 76(5), 965(2008), DOI:10.1016/j.talanta.2008.05.019

30. M. Jain, U. Chandrakant, V. Orsat and V. A. Raghavan, Industrial Crops and Products, 114, 28(2018), DOI:10.1016/j.indcrop.2018.01.051

31. Y. H. Chan, S. Yusup, A. T. Quitain, Y. Uemura and S. K. Loh, Biomass and Bioenergy, 107, 155(2017), DOI:10.1016/j.biombioe.2017.10.005

32. H. Benmoussa, W. Elfalleh, S. He, M. Romdhane, A. Benhamou and R. Chawech, Industrial Crops and Products, 124, 633(2018), DOI:10.1016/j.indcrop.2018.08.036

33. L. G. Bach, T. V. Tran, D. T Nguyen, T. V. Pham and S. T. Do, Research on Chemical Intermediates, 44(3), 1661(2018), DOI:10.1007/s11164-017-3191-1

34. T. H. Tran, P. T. N. Nguyen, D. T. Nguyen, V. T. T. Ho and L. G. Bach, Solid State Phenomena, 279, 217(2018), DOI:10.4028/www.scientific.net/SSP.279.217

35. P. T. N. Nguyen, T. H. Tran, T. H. N. Le, N. Q. A. Pham, T. H. Le, T. C. T. Nguyen, D. T. Nguyen and L. G. Bach, Solid State Phenomena, 279, 235(2018), DOI: 10.4028/www.scientific.net/SSP.279.235

36. T. V. Tran, Q. T. P. Bui, T. D. Nguyen, V. T. T. Ho and L. G. Bach, Water Science and Technology, 75(9), 2047(2017), DOI:10.2166/wst.2017.066

37. T.V Tran, T. P. Q. Bui, T. D Nguyen and L. G. Bach, Surfaces and Interfaces, 6, 209(2017), DOI:10.1016/j.surfin.2016.10.007

38. T. V. Tran, Q. T. P. Bui, T. D. Nguyen, N. T. H. Le and L. G. Bach, Adsorption Science \& Technology, 35(1-2), 72(2017), DOI:10.1177/0263617416669152

39. V. T. Tran, D. T. Nguyen, V. T. T. Ho, P. Q. H. Hoang, P. T. Q. Bui and L. G. Bach, L.G. Journal of Materials and Environmental Science, 8(2), 426(2017)

40. V. T. Tran, T. H. V. Thi, D. T. Nguyen, T. T. Nguyen, T. P. Q. Bui and L. G. Bach, Carbon - Science and Technology, 8(4), 63(2016)

41. D. Belhachat, L. Mekimene, M. Belhachat, A. Ferradji and F. Aid, Journal of Applied Research on Medicinal and Aromatic Plants, 9, 132(2018), DOI:10.1016/j.jarmap.2018.04.003

42. B. Suryawanshi and B. Mohanty, Journal of Environmental Chemical Engineering, 6(2), 2660(2018), DOI:10.1016/j.jece.2018.04.014

43. D. K. Yanık, $L W T$, 77, 45(2017), DOI:10.1016/j.lwt.2016.11.020

44. B. Hu, K. Zhou, Y. Liu, A. Liu and Q. Zhang, Industrial Crops and Products, 115, 290(2018), DOI: $10.1016 /$ j.indcrop.2018.02.034

45. O. Ekundayo, O. Bakare, A. Adesomoju and E. Stahl-Biskup, Journal of Essential Oil Research, 2(4), 199(1990), DOI:10.1080/10412905.1990.9697861

46. G. Kirbaslar and S. I. Kirbaslar, Journal of Essential Oil Research, 16(2), 105(2004), DOI:10.1080/10412905.2004.9698663

47. A. G. Fakim and F. Demarne, Journal of Essential Oil Research, 7(1), 105(1995), DOI: $10.1080 / 10412905.1995 .9698477$

48. S. Riela, M. Bruno and C. Formisano, Journal of Essential Oil Research, 31(6-7), 1110(2008), DOI: $10.1002 /$ jssc. 200700425

[RJC-5107/2018] 